\title{
Blood group and Human Leucocyte Antigen sub- type as determinants to keloid formation and Recurrence in Keloid Patients; A prospective longitudinal cohort study
}

Ferdinand Nangole ( $\square$ nangole2212@gmail.com )

University of Nairobi

Kelsey Ouyang

University of California, Los Angeles

George Agak

University of California, Los Angeles

Julius Ogeng'o

University of Nairobi

Anzala Omu

University of Nairobi

\section{Research Article}

Keywords: Blood group, Human Leucocyte Antigen, keloid, Recurrence

Posted Date: April 19th, 2021

DOI: https://doi.org/10.21203/rs.3.rs-421812/v1

License: (c) (1) This work is licensed under a Creative Commons Attribution 4.0 International License.

Read Full License 


\section{Abstract}

The role of genetic factors in keloid is a firmed by the fact that keloids have been shown to occur among members of the same family.. We undertook this study to determine whether there is any association between patients' bloodgroup and HLA sub-types to keloids and keloid recurrence. This was a prospective longitudinal study of patients with keloids and a control of patients managed for other surgical conditions with no keloids. Blood was taken from each patient and analysed for blood group and HLA sub-types using the sequence specific primer geno-typing. Data captured were summarized and analysed using students T-test to compare means. Probability values significance was at 0.05 .

A total of 90 patients with keloids and 59 in a control group were followed up in the study. The male to female ratio of the patients was 2:1. The most common blood group for both groups was blood group 0 at $51.3 \%$ and $49.2 \%$, followed by blood group $A$ and $B$ respectively. Patients with keloids had a significantly higher positive alleles with DQA*01, DQB1*05, DQB1*06 and DRB1*15. There was an association between blood group $\mathrm{A}$ and $\mathrm{DQB} 1 * 06$ and recurrence. In conclusion, this study demonstrates that there is significant difference in HLA sub-types among patients who form keloids and the non-keloid forming patients among our study cohorts. Salient differences were also noted in patients with keloid recurrence based on their blood group, a pointer to the significance of genetic factors in keloid pathogenesis and severity.

\section{Introduction}

Pathogenesis of keloid disease is still not well established. Keloid occurrence has generally been classified as sporadic, in individuals with no known members of the family with keloids or familial where members of a given family have positive history of keloids. Familial keloids have been shown to contribute to about 50 per cent of keloid patients indicating a strong inheritance pattern in the pathophysiology of the disease [1].A number of pedigree studies have demonstrated keloids to either have an autosomal or recessive mode of inheritance[2-3]. Other studies have suggested $X$ linked mode of inheritance [4]. HLA studies have demonstrated some consistentassociation with some sub-types and keloid formation especially HLA DRB*16 sub-type [5]. Majority of these studies have however been done in populations with low keloid prevalence with non in Africa, a keloid endemic zone.An association between $\mathrm{ABO}$ blood groupingand keloids have also been documented by a number of authors [6]. Keloids have high recurrence rates irrespective of the treatment modalities provided [7-8]. Whether a patient's genetic factors influence keloid recurrence has not been demonstrated. We undertook this study to demonstrate any significant differences between various blood groups andHLA sub-types in patients with keloids and those without and to determine whether they could influence keloid recurrence.

\section{Materials And Methods}

Patients with keloids were involved in the design of the study through pretested questionnaires to determine the most common clinical features of keloid recurrence.All methods were carried out in 
accordance with relevant guidelines and regulations. The study was approved by the local ethics and research committee. Informed consent was sort from all patients to participate in the study. For the minors informed consent was taken from the parents or legally acceptable representatives. Patients with keloids managed by surgical excision and a control with no keloids were followed up for a minimum duration of one year. History and physical examination was taken. Pain and pruritus scores were done using the respective visual analogue scores. This was repeated at regular intervals during the follow up period. The control group was of patients admitted for elective surgical procedures with no keloids nor family history of keloids. They were followed up for one year to determine if they would also formkeloids. From each patient, blood was taken and analysed for blood group and HLA sub-types.HLA typing was done using sequence specific primer geno-typing. All patients with keloids had surgical excisionby a senior plastic surgeon. Peri-operative management of the patients was similar.Post-surgery all patientswith keloids weresubjected to superficial radiotherapy within 24 hours of surgery.Recurrence was defined as keloid regrowth or worsening pain and or pruritus requiring medical intervention. Data captured were summarized and analysed using students T-test to compare means. Probability values significance was at 0.05 .

\section{Results}

A total of 90 patients with 104 keloids and a control group of 59 patients were followed up during the study. The male to female ratiowas 1:2 with 60 females and 30 male patients. For the control group the male to female ratio was 1:2 with 39 female and 20 male patients. The age rangewas 15 to 65 years with a mean age of 29.5 and a median age of $20-25$ years. The age range for control patients was 15.5 to 64 years with mean age of 29.7 years and a median ageof 20-25 years. There was no statistical significance difference between the keloids group and the control population (Table 1). The anatomical location of the keloids were as follows; ears $(n=47)$, abdomen $(n=10)$, cheek $(n=15)$, upper $\operatorname{limb}(n=5)$, back $(n=13)$, chest and neck $(n=13)$ and scalp $(n=1)$. All 90 patients and control had their blood taken for blood groups while 80 of the 90 patients had their blood taken for HLA studies. Eighteen patients of the 80 had keloid recurrence (KR) while 62 did not have any form of recurrence (NKR).

The most common blood group for patients with Keloidsand the control group with no keloids was blood group 0 at $51.3 \%$ and $49.2 \%$ ( $p$-value 0.552 ), followed by blood group A and B respectively. There was no statistical significance difference in the blood groups of patients who formed keloids and the control group(Table2).

Comparison between blood groups in patients with KR and NKR patients demonstrated that keloid patients with blood group A were more prone to recurrence compared to the other blood groups ( $p$-value $<0.011)$ while patient with blood group B were list likely to have keloid recurrence $(p$-value $<0.001)$ (Table3).

Out of 90 patients with keloids who were followed up in the study 80 patients had their blood analysed for HLA. Of the 80patients 18 had keloid recurrence (KR)and 62 had no recurrence (NKR).Comparison of 
the HLA sub-types between the control group and patients who had keloids showed significance differences in the alleles of HLADQA $1 * 01, \mathrm{DQB} 1 * 05, \mathrm{DQB} 1 * 06$, and DRB $1 * 15$ all in favour of patients who had keloids (Table4). Analysis of HLA sub-types between patients who had keloids recurrence (KR) and those without (NKR), revealed DQBI*06 to be significantly elevated in the keloid recurrent group(Table5).

\section{Discussion}

The influence of genetic factors in keloid formation could be extrapolated from the facts that keloids seem to portray a distinct pattern of inheritance and a strong familial tendency [1-3]. Though not unique to keloids, genetic factor have been shown to have an influence on various disease processes whether infective benign or malignant origin. Most studied and easily applied genetic variants have been the ABO and the HLA systems probably due to the fact that they are routinely used during blood transfusions aswell as tissue typing and organ transplants. Our study noted significant associations between this two genetic systems of the body and keloid patients.

The role and influence of $A B O$ blood groups in the pathogenesis and outcome of keloid management has been established before. Ramma kishnan et al in India found blood group A to be significantly higher in patients with keloids than in the normal population [9].These findings were similar to those of Shaheen et al. in a Syrian study recently who found blood group A to be significantly more common in patients with keloids than in the normal cohort [6]. However, Abbas Moure Toure in Togo, like in our study demonstrated no statistical significance difference with blood groups in patents with keloids and a control population of patients who presented with other dermatological conditions [10]. Our study on the other hand found keloid patients with blood group $A$ to be more prone to keloid recurrence compared to the other blood group with blood group $B$ being less prone to recurrence.

Human leucocyte Antigen ( $\mathrm{HLA}$ ), key genes responsible for the development of the cellular immune system, have been shown to play a critical role in not only autoimmune conditions but also in benign and malignant conditions.Mutations on some of the alleles are thought to be responsible for the development of a number of autoimmunedisorders such as celiac disease, anky losing, spodylisthesis and rheumatoid arthritis[11-12]. Even closer to keloids Sclerotic skin conditions such as sarcoidosis and systemic sclerosis have also been shown to have associations with particular alleles [13].Though keloids disease are not classified as autoimmune disease several studies have shown an association between some alleles and the disease bringing to the fore possibilities that the immune system could play a critical role in keloid formation. Wen-Sheng Lu found DQB1*0501, B*07-DRB1*15, DQB1*0503-DRB1*15 $(P<0.05)$ to be associated with keloid formation among Chinese Ham patients cohorts [14]. Another study by Brownet affound an association between HLA DRB $1 * 15$ and keloid formation in apatient cohort of Caucasians [15]. However, in a study in the Caribbean with Brown et alno association was demonstrated between HLA DRB* 15 alleles and keloid patients of African descent [16]. Inour study we demonstrated HLA alleles DQA*01, DQB $1 * 05, \mathrm{DQB} 1 * 06$ and DRB $1 * 15$ to be significantly associated with keloid patients. Even further Allele DQB1*06 were found to be significantly associated with keloid recurrence. 
Our study findings seems to add more evidence to the fact that keloid pathogenesis and recurrence seem to be influenced by the individual's immune system. The exact mechanism on how this is achieved is still not clear and probably requires mores studies. It is however postulated that certain alleles such as DRB $1 * 15$ may be more efficient at antigen binding and presentation to the antigen presenting cells following trauma or any injury leading to a stronger inflammatory and proliferative phase of wound healing resulting in massive collagen deposition akin to keloid formation [13]. Evidence of the strong inflammatory response in keloid patients include the fact that keloid patients in a number of studies have been shown to have elevatedpro-inflammatory cytokines compared to the normal population suggesting a pro-inflammatory state of the body [17-19 ]. Majority of keloid specimens also have been shown to have a high concentration of inflammatory cells such as macrophages, lymphoctyes and mast cells [20]. Further normal fibro-blasts in vitro subjected to inflammatory cytokines such as interleukin 6 have responded by massive synthesis of collagen fibres. These activities were stopped by antibodies against interleukin 6 implying that abnormal fibro-blast activity in keloid patient is secondary to inflammatory response by cytokines $[18,21]$.

\section{Conclusion}

Keloid patho-physiology from our study findings seem to be influenced by the genetic composition of the patients. Patients with blood group A are more prone to keloid recurrence a possible indication of the disease severity in this group of patients. While a number of HLA sub-types were identified to be significantly associated with keloid disease in our cohort, HLA DRB $1 * 15$ has also been noted in several other studies from different patient population to be associated more with the disease. There is need to carry out more research on this particular loci on its role on keloid formation. The association between several type 2 alleles and keloid formation in our study and other studies strongly suggest an immunological aspect in keloid formation.

\section{Declarations}

Funding statement: This work was supported by Foundation National institute of Health grant number K01AR071479

Conflict of interest. There is no conflict of interest to declare

Availability of Data/Material. The data for this study will be availed at the University of Nairobi repository

\section{Authorship Statement:}

Conceptualization: , Nangole FW , Ogeng'o J ,Omu A;

Methodology: Nangole FW , Ogeng'o J ,Omu A; 
Formal analysis and investigation: Nangole FW, Agak G ,Ouoyang K

Writing - original draft preparation: Nangole FW ];

Writing - review and editing: Nangole FW, Agak G ,Ouoyang K

Funding acquisition: : Nangole FW, Agak G ,Ouoyang K

Resources: Nangole FW, Agak G ,Ouoyang K Omu A

Supervision: Ogeng'o J , Omu A,gak G

Ethical Approval . This study was approved by the KNH/ERC Board at the University of Nairobi /KNH

\section{References}

1. Kouotou, E.A.,Nansseu .J.R., Guissana E.O., Menye C.R., AkpadjanF.A (2019).Epidemiology and clinical features of keloids in Black Africans: a nested case-control study from Yaounde, Cameroon.Int J Dermatol, 58(10): p. 1135-1140.

2. Clark . J.A.,Maria. L. T., Howard .L, Horia.S., Robert .K. and Jeffrey B K (2009) Description of familial keloids in five pedigrees: evidence for autosomal dominant inheritance and phenotypic heterogeneity. BMC Dermatol, 9: p. 8-12

3. Glass, D.A.,(2017) Current Understanding of the Genetic Causes of Keloid Formation. J Investig Dermatol Symp Proc, 18(2): p. S50-S53.

4. Marneros .A.G.,James E.C., Norris.M.D.;Bjorn R. O.I.,(2001) Clinical genetics of familial keloids.Arch Dermatol, 137(11): 1429-34.

5. Brown. J.J., Ollier. W.E., Thomson. W., Bayat. A. (2008) Positive association of HLA-DRB1*15 with keloid disease in Caucasians. Int J Immunogenet, 35(4-5):303-7. doi: 10.1111/j.1744313X.2008.00780.x. PMID: 18976433

6. Shaheen, A., J. Khaddam, and F. Kesh,(2016) Risk factors of keloids in Syrians.BMC Dermatol, 16(1): p. 13.

7. Chuma J.C, Patrick D.C.,(2009) Keloids Pathogenesis, clinical features and management, Plastic Surgery; 8:34-4

8. BrissettA., Sherris D.A.(2001) Scar contractures, hypertrophic scars, and keloids. Facial Plast. Surg, 17:263-272.

9. Ramakrishnan K.M., Thomas K.P., Sundararajan C.R.(1974), Study of 1000 patients with keloids in South India. Plast.Reconstr.Surg., 53:276-280

10. Abas Mouhari-Toure, BayakiSaka, Koussaké Kombaté, SefakoAkakpo, PalakiyemEgbohou, KissemTchangaï-Walla, PalokinamPitche, (2012)"Is There an Association between Keloids and Blood Groups?" International Scholarly ResearchNotices,ArticlelD 750908, 4 pages, 2012. https://doi.org/10.5402/2012/750908 
11. GergelyBodis, Victoria Toth and Andreas Schwarting,(2018) Role of Human Leukocyte Antigens (HLA) in Autoimmune Diseases Rheumatology and Therapy vol 5, pages5-20

12. SantosoCornain(1995), The Significance of HLA-antigens in dermatology Medical Journal of Indonesia, 4(1):44, DOI: 10.13181/mji.v4i1.905

13. McCarty SM, Syed F, Bayat A.(2010) Influence of the human leukocyte antigen complex on the development of cutaneous fibrosis: an immune-genetic perspective. ActaDermVenereol., 90(6):56374. doi: 10.2340/00015555-0975. PMID: 21057738.

14. Wen-Sheng Lu, Xian-Bo Zuo, Zai-Xing Wang, Li-QiongCai, Fei Zhu, Yang Li, et al (2011) Association of HLA haplotype with keloids in Chinese Hans. Burns.. 2011 Aug;37(5):794-9

15. J J Brown W. E. R Ollier W Thomson,(2008) Positive association of HLA-DRB1*15 with keloid disease in Caucasians, International Journal of Immuno-genetics:,35(4-5):303-7

16. J. J. Brown W. E. R. Ollier G. Arscott A. Bayat(2010) Association of HLA-DRB1* and keloid disease in an Afro-Caribbean population, Clin Exp Dermatol., 35(3):305-10.doi: 10.1111/j.13652230.2009.03506.x. Epub 2009 Oct 23.

17. Robert L McCauley, Vimlerani Chopra,(1992) Altered cytokines production in Black patients with keloids Journal of clinical Immunology, 12;300-308

18. Qunzhou Zhang, Takayoshi Yamaza, A. Paul Kelly,(2009)Tumor-Like Stem Cells Derived from Human Keloid Are Governed by the Inflammatory Niche Driven by IL-17/IL-6 Axis PLOS 4(11): e7798.

19. Xue, H., McCauley, R. L., and Zhang, W,(2000) Elevated interleukin-6 expression in keloid fibroblasts. Journal of Surgical Research., 89(1), 74-77

20. M.M. Ali, F.W. Karanja, F.W. Nang'ole, E.O.N. Opot, K.O. Mulehane,D.Z.Mbithi(2019)Determination of the prevalence, clinical characteristics and histo-pathological features of keloids in patients managed at the Kenyatta National Hospital. East Afri. Med. J, 2019; 96(1); 2220-2229

21. Mohammed Ghazizadeh, MamikoTosa(2007) Functional implications of IL-6 signalling pathways in keloid pathogenesis Journal of investigative dermatology, 127;1:98-105

\section{Tables}

Table 1: Age of patients with keloids and the control group 


\begin{tabular}{|l|l|l|}
\hline Age of presentation (years) & Keloid group & Control group \\
\hline $10-15$ & 3 & 2 \\
\hline $15-20$ & 19 & 10 \\
\hline $20-25$ & 18 & 14 \\
\hline $25-30$ & 15 & 12 \\
\hline $30-35$ & 12 & 8 \\
\hline $35-40$ & 10 & 6 \\
\hline $40-45$ & 7 & 4 \\
\hline $45-50$ & 4 & 3 \\
\hline$>50$ & 2 & 2 \\
\hline Total & 90 & 59 \\
\hline
\end{tabular}

Table2: Blood group types for patients with keloids and those without

\begin{tabular}{|c|c|c|c|c|}
\hline \multirow[t]{2}{*}{ Blood group } & Total Count & Keloids $\mathbf{N}=90$ & Control $N=59$ & \multirow[t]{2}{*}{ P-Value } \\
\hline & & $\mathbf{N}(\%)$ & $\mathbf{N}(\%)$ & \\
\hline $\mathrm{O}$ & 75 & $46(51.3)$ & $29(49.2)$ & 0.552 \\
\hline $\bar{A}$ & 45 & $28(31.3)$ & $17(28.8)$ & 0.480 \\
\hline $\mathrm{B}$ & 23 & $12(13.7)$ & $11(18.6)$ & 0.175 \\
\hline $\mathrm{AB}$ & 6 & $4(3.7)$ & $2(3.4)$ & 0.932 \\
\hline
\end{tabular}

Table 3: Comparison of blood groups in patients with keloids recurrence (KR) and those without (NKR).

\begin{tabular}{|c|c|c|c|c|}
\hline $\begin{array}{l}\text { Blood } \\
\text { group }\end{array}$ & $\begin{array}{l}\text { Total } \\
\text { Count }\end{array}$ & $\begin{array}{c}\text { Non Recurrent } \mathbf{N}= \\
71\end{array}$ & $\begin{array}{c}\text { Recurrent } \mathbf{N}= \\
19\end{array}$ & $\begin{array}{l}\text { P- } \\
\text { Value }\end{array}$ \\
\hline & & $\mathbf{N}(\%)$ & $\mathbf{N}(\%)$ & \\
\hline $\mathrm{O}$ & 45 & $35(50.0)$ & $10(55.6)$ & 0.124 \\
\hline $\mathrm{A}$ & 28 & 19(29.00) & $9(38.9)$ & 0.011 \\
\hline $\mathrm{B}$ & 13 & $13(17.7)$ & 0 & $<0.001$ \\
\hline$\overline{\mathrm{AB}}$ & 4 & $4(3.3)$ & 0 & 0.516 \\
\hline
\end{tabular}

Table 4: HLA sub-types comparison between patients with keloids and normal controls 


\begin{tabular}{|c|c|c|c|c|c|}
\hline & \multicolumn{2}{|c|}{ Keloids $\mathbf{N}=80$} & \multicolumn{2}{|c|}{ Control $\mathbf{N}=59$} & \multirow[b]{2}{*}{ P-Value } \\
\hline Allele & $\begin{array}{c}\text { Allele +ve } \\
\text { N (\%) }\end{array}$ & $\begin{array}{c}\text { Allele -ve } \\
\mathbf{N}(\%)\end{array}$ & $\begin{array}{c}\text { Allele +ve } \\
\mathbf{N}(\%)\end{array}$ & $\begin{array}{c}\text { Allele -ve } \\
\text { N (\%) }\end{array}$ & \\
\hline$\overline{\mathrm{DQA} 1 * 01}$ & $67(83.8)$ & $13(16.2)$ & $26(44.1)$ & $33(55.9)$ & $<0.001$ \\
\hline DQA1*02 & $4(5.0)$ & $76(95.0)$ & $8(13.6)$ & $54(91.5)$ & 0.129 \\
\hline DQA1*03 & $7(8.8)$ & $73(91.3)$ & $8(13.6)$ & $51(86.4)$ & 0.415 \\
\hline DQA1*04 & $6(7.5)$ & $74(92.5)$ & $3(5.1)$ & $56(94.9)$ & 0.733 \\
\hline DQA1*05 & $41(51.3)$ & $39(48.7)$ & $28(47.5)$ & $31(52.5)$ & 0.732 \\
\hline$\overline{\mathrm{DQA} 1 * 06}$ & $5(6.3)$ & $75(93.7)$ & $4(6.8)$ & $55(93.2)$ & 1 \\
\hline$\overline{\mathrm{DQB} 1 * 01}$ & $3(3.8)$ & $77(96.2)$ & $1(1.7)$ & $58(98.3)$ & 0.637 \\
\hline DQB1*02 & $8(10.0)$ & $72(90.0)$ & $5(8.5)$ & $54(91.5)$ & 1 \\
\hline$\overline{\mathrm{DQB} 1 * 03}$ & $18(22.5)$ & $62(77.5)$ & $14(23.7)$ & $45(76.3)$ & 1 \\
\hline DQB1*04 & $16(20.0)$ & $64(80.0)$ & $12(20.3)$ & 47(79.7) & 1 \\
\hline DQB1*05 & $44(55.0)$ & $36(45.0)$ & $18(30.5)$ & $41(69.5)$ & 0.006 \\
\hline DQB1*06 & $44(55)$ & $36(45)$ & 0 & $59(100)$ & 0.001 \\
\hline DQB1*07 & $1(1.3)$ & 79(98.7) & 0 & $59(100)$ & 1 \\
\hline DRB1*01 & DQ16(20.0) & $64(80.0)$ & $16(27.1)$ & $43(72.9)$ & 0.415 \\
\hline DRB1*02 & $2(2.5)$ & $78(97.5)$ & $3(5.1)$ & $56(94.9)$ & 0.650 \\
\hline $\mathrm{DRB}^{*} 03$ & $19(23.8)$ & $61(76.2)$ & $15(25.4)$ & $44(74.6)$ & 0.844 \\
\hline DRB1*04 & $9(11.3)$ & $71(88.7)$ & $4(6.8)$ & $55(93.2)$ & 0.557 \\
\hline DRB1*05 & $5(6.3)$ & $75(93.7)$ & $3(5.1)$ & $56(94.9)$ & 1 \\
\hline $\mathrm{DRB}^{*}{ }^{*} 06$ & $3(3.8)$ & $77(96.2)$ & 0 & $59(100)$ & 0.086 \\
\hline DRB1*07 & $5(6.3)$ & $75(93.7)$ & $8(13.6)$ & $51(86.4)$ & 0.155 \\
\hline$\overline{\mathrm{DRB}} 1 * 08$ & $6(7.5)$ & $74(92.5)$ & $4(6.8)$ & $55(93.2)$ & 1 \\
\hline DRB1*09 & $1(1.3)$ & $79(98.7)$ & $2(3.4)$ & $57(96.6)$ & 0.574 \\
\hline DRB1*10 & $2(2.5)$ & $78(97.5)$ & 0 & $59(100)$ & 0.508 \\
\hline DRB1*11 & $13(16.3)$ & $67(83.7)$ & $9(15.3)$ & $50(84.7)$ & 1 \\
\hline$\overline{\mathrm{DRB}} 1 * 12$ & $3(3.8)$ & $77(96.3)$ & $2(3.4)$ & $57(96.4)$ & 1 \\
\hline DRB1*13 & $10(12.5)$ & $70(87.5)$ & $8(13.6)$ & $51(86.4)$ & 1 \\
\hline DRB1*14 & $6(6.3$ & $75(93.7)$ & $4(6.8)$ & $55(93.2)$ & 1 \\
\hline DRB1*15 & $42(52.5)$ & $38(47.5)$ & $13(22.0)$ & $46(78.0)$ & 0.004 \\
\hline DRB1*16 & $1(1.3)$ & $79(98.7)$ & $2(3.4)$ & $57(96.6)$ & 0.574 \\
\hline
\end{tabular}

Table5: HLA sub-types analysis between patients with keloid recurrence $(\mathrm{KR})$ and those without (NKR) revealed statistical significance difference with HLA allele DQB1*06 


\begin{tabular}{|c|c|c|c|c|c|}
\hline & Non Recurrent $\mathrm{K}$ & is $(\mathrm{NKR}) \mathrm{N}=$ & $\begin{array}{l}\text { Keloid rec } \\
(\mathrm{KR}) \\
\mathrm{N}=18\end{array}$ & irrent & $\begin{array}{l}P \\
\text { Value }\end{array}$ \\
\hline Allele & $\begin{array}{c}\text { Allele +ve } \\
\text { N (\%) }\end{array}$ & $\begin{array}{c}\text { Allele -ve } \\
\text { N (\%) }\end{array}$ & $\begin{array}{l}\text { Allele +ve } \\
\text { N (\%) }\end{array}$ & $\begin{array}{c}\text { Allele -ve } \\
\text { N (\%) }\end{array}$ & \\
\hline $\mathrm{DQA1}^{*} 01$ & $50(80.6)$ & $12(19.4)$ & $17(94.4)$ & $1(5.6)$ & 0.278 \\
\hline DQA1*02 & $3(4.8)$ & $59(95.2)$ & $1(5.6)$ & $17(94.4)$ & 1 \\
\hline DQA1*03 & $7(11.3)$ & $55(88.7)$ & 0 & $18(100)$ & 0.340 \\
\hline DQA1*04 & $5(8.1)$ & $57(91.9)$ & $1(5.6)$ & 17(94.4) & 1 \\
\hline DQA1*05 & $30(48.4$ & $32(51.6)$ & $11(61.1)$ & $7(38.9)$ & 0.426 \\
\hline DQA1*06 & $3(4.8)$ & $59(95.2)$ & $2(11.1)$ & $16(88.9)$ & 0.313 \\
\hline DQB1*01 & $3(4.8)$ & $59(95.2)$ & 0 & $18(100)$ & 1 \\
\hline DQB1*02 & $5(8.1)$ & $57(91.9)$ & $3(16.7)$ & $15(83.3)$ & 0.370 \\
\hline$\overline{\mathrm{DQB} 1 * 03}$ & $14(22.6)$ & $48(477.4)$ & $4(22.2)$ & $14(77.8)$ & 1 \\
\hline$\overline{\mathrm{DQB} 1 * 04}$ & $11(17.7)$ & $51(82.3)$ & $5(27.8)$ & $13(72.2)$ & 0.338 \\
\hline $\mathrm{DQB}^{*}{ }^{*} 05$ & $36(58.1)$ & $26(41.9)$ & $8(44.4)$ & $10(55.6)$ & 0.421 \\
\hline $\mathrm{DQB1}^{*} 06$ & $30(48.4)$ & $32(51.6)$ & $14(77.8)$ & $4(22.2)$ & 0.033 \\
\hline DQB1*07 & 0 & $62(100)$ & $1(5.6)$ & $17(94.4)$ & 0.225 \\
\hline $\mathrm{DRB}^{*} 01$ & $13(21.0)$ & $49(79.0)$ & $3(16.7)$ & $15(83.3)$ & 1 \\
\hline $\mathrm{DRB} 1 * 02$ & $1(1.6)$ & $61(98.4)$ & $1(5.6)$ & $17(94.4)$ & 0.402 \\
\hline DRB1*03 & $14(22.6)$ & $48(77.4)$ & $5(27.8)$ & $16(72.2)$ & 0.754 \\
\hline DRB1*04 & $6(9.7)$ & $56(90.3)$ & $3(16.7)$ & $15(83.3)$ & 0.413 \\
\hline DRB1*05 & $5(6.5)$ & $58(93.5)$ & $1(5.6)$ & $17(94.4)$ & 1 \\
\hline$\overline{\mathrm{DRB} 1 * 06}$ & $3(4.8)$ & $59(95.2)$ & 0 & $18(100)$ & 1 \\
\hline$\overline{\mathrm{DRB} 1 * 07}$ & $4(6.5)$ & $58(93.5)$ & $1(5.6)$ & 17(94.4) & 1 \\
\hline DRB1*08 & $4(6.5)$ & 58(93.5) & $2(11.1)$ & $16(88.9)$ & 0.612 \\
\hline DRB1*09 & 0 & $62(100)$ & $1(5.6)$ & $17(94.4)$ & 0.225 \\
\hline DRB1*10 & $1(16)$ & $61(98.4)$ & $1(5.6)$ & $17(94.4)$ & 0.402 \\
\hline DRB1*11 & $9(14.5)$ & $53(85.5)$ & $4(22.2)$ & $14(77.8)$ & 0.475 \\
\hline DRB1*12 & $3(4.8)$ & $59(95.2)$ & 0 & $18(100)$ & 1 \\
\hline DRB1*13 & $9(14.5)$ & $53(85.5)$ & $1(5.6)$ & $17(94.4)$ & 0.442 \\
\hline DRB1*14 & $4(6.5)$ & $58(93.5)$ & $1(5.6)$ & $17(94.4)$ & 1 \\
\hline DRB1*15 & $34(58.8)$ & $28(45.2)$ & $8(44.4)$ & $10(55.6)$ & 0.593 \\
\hline DRB1*16 & $1(1.6)$ & $61(98.4)$ & 0 & $18(100)$ & 1 \\
\hline
\end{tabular}

